\title{
Artificial rearing of young lambs
}

630.4

C212

P 1507

1990

$\mathrm{OOAG}$

c. 3

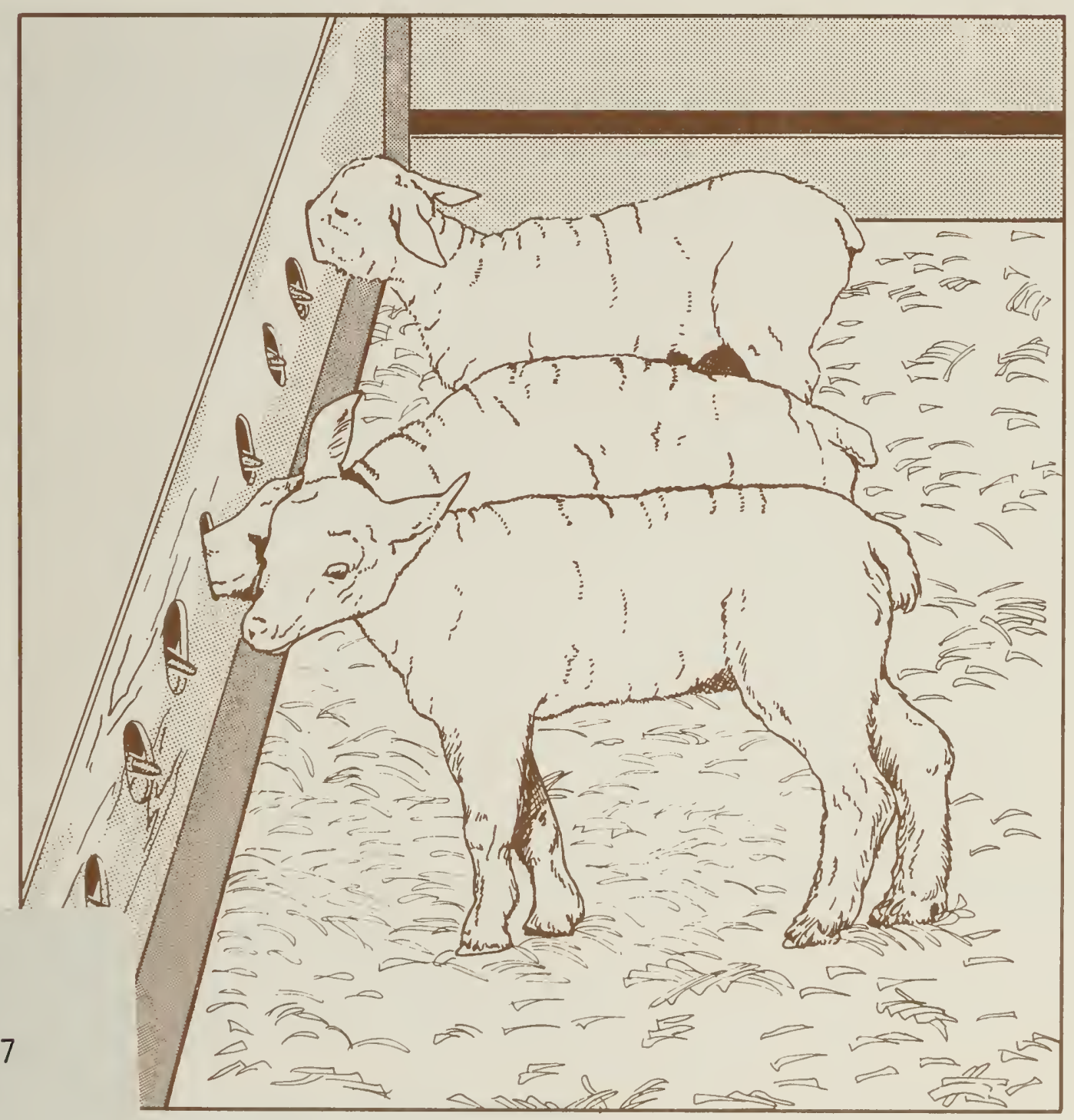

Canadä 
Digitized by the Internet Archive in 2012 with funding from

Agriculture and Agri-Food Canada - Agriculture et Agroalimentaire Canada 


\title{
Artificial rearing of young lambs
}

Original by
A.D.L. Gorrill, G.J. Brisson, D.B. Emmons, and G.J. St-Laurent
First revision by
J.W.G. Nicholson
Second revision by D.P. Heaney and D.A. Leger
Animal Research Centre
Ottawa, Ontario

\author{
Agriculture Canada Publication 1507/E \\ available from \\ Communications Branch, Agriculture Canada \\ Ottawa K1A 0C7 \\ ${ }^{\odot}$ Minister of Supply and Services Canada 1990 \\ Cat. No. A63-1507/1990E ISBN 0-662-17341-4 \\ Printed 1972 Revised 1978 Revised 1982 Reprinted 1985 Reprinted 1989 \\ Revised 1990 4M-6:90




\section{PREFACE}

The original version of this publication was printed in 1972 . It was revised by the original authors in 1978 and received a major revision by J.W.G. Nicholson in 1982. A debt of gratitude is due to the authors of the previous editions, which have served the Canadian sheep industry well.

As a result of the continued strong interest in artificial rearing of young lambs, this revision has been prepared to further update the guidelines. It draws heavily on research results from both the United States and Canada. This publication has also had significant input from the extensive research and experience at the Animal Research Centre (ARC) in Ottawa where more than 50000 lambs were reared artificially during the period of 1970-1989. 


\section{CONTENTS}

Preface 4

Highlights 6

Introduction 7

Selecting and preparing lambs 7

Minimizing unnecessary artificial rearing 7

Feeding colostrum 8

Removal from the ewe 9

Teaching lambs to drink milk replacer 9

Grouping lambs by size and age 11

Artificial rearing management 11

Feeding techniques 11

Water and creep feed 12

Temperature of milk replacer 13

Weaning lambs early 14

Choice of milk replacer 14

Types 14

Preparation 16

Adding formalin 16

Feeding systems 17

Protecting the nipples 17

Feeding from a nipple pail 17

Multiple-nipple containers 18

Teat bars 19

Sanitation and cleaning 24

Lamb diseases and digestive upsets 25

Performance of lambs raised on milk replacer 25

Additional reading 26 


\section{HIGHLIGHTS}

Milk replacer formulas and feeding and management systems have been developed to raise very young lambs successfully on milk replacer. Economical technology exists to rear artificially the extra lambs from prolific breeds that produce more lambs than the ewes can raise themselves, as well as lambs that would otherwise be orphaned by lack of maternal milk supply, death of the dam, or rejection. Artificial rearing is not recommended for the entire lamb crop.

Successful artificial rearing on milk replacer depends on the following:

- Be sure that lambs receive colostrum soon after birth either by nursing at least $6 \mathrm{~h}$, or by bottle feeding $50 \mathrm{~mL}$ per kilogram of body weight.

- Remove lambs from their dams as soon as possible after they have received colostrum, which makes training easier.

- Ensure that lambs are trained to nurse from the artificial nipples but do not overtrain.

- Use milk replacers that contain about $24 \%$ fat and $24 \%$ protein in the dry form for best results.

- Mix the milk replacer to contain 16-20\% solids for feeding.

- Add 0.05-0.10\% of formalin to the liquid milk replacer to inhibit bacterial growth and souring and to reduce abomasal bloat (before use, read section on "Adding formalin").

- Use a teat bar for a simple, cheap, and effective method of feeding groups of lambs. Shields are required around the nipples to prevent lambs from chewing them.

- Feed lambs that are about the same age and weight in groups of 12 or fewer. Most lambs adapt quickly to the feeding system and learn to suck the nipples within 1 or 2 days.

- Feed milk replacer ad libitum. Lambs will perform equal to, or better than, those sucking the ewe.

- Clean the milk-replacer feeding system and utensils regularly and always use sanitary methods.

- Provide clean, fresh water; a palatable, highly nutritious creep feed containing $17-20 \%$ protein; and high-quality alfalfa hay at all times.

- Inject lambs with vitamins $\mathrm{A}, \mathrm{D}, \mathrm{E}$, and with selenium if white muscle disease is a problem in your district.

- Vaccinate with a multiple clostridia vaccine for enterotoxemia (pulpy kidney).

Management is the most important single factor that will determine success or failure! 


\section{INTRODUC'TION}

Artificial rearing is the practice of removing very young lambs from their mothers and raising them on milk replacer. The practice is increasing, probably because of the use of prolific breeds, which produce more lambs than the ewes can raise themselves. Recommended artificial rearing methods are both useful and profitable ways by which to raise those extra lambs, as well as lambs that would otherwise be orphaned by lack of maternal milk supply, death of the dam, or rejection.

Orphan lambs have been reared artificially for a long time. Sometimes whole cow's milk was fed but more commonly skim milk was used, often with unsatisfactory rewards for the high expenditure of food and effort. Much of the initial research to develop effective milk replacers and the management systems for artificial rearing of lambs was done in Europe, where extensive dairy-sheep industries existed for the production of cheese.

During the early development of synthetic milk replacers, researchers found that feeding spray-dried, full-cream cow's milk resulted in gains similar to those obtained either with natural rearing or with lambs reared artificially on fresh or reconstituted, frozen ewe's milk. However, the cost of using reconstituted, spray-dried, fullcream cow's milk was prohibitive under practical conditions. Thus, synthetic milk replacers were developed that were based on spraydried skim milk and mixtures of animal and vegetable fats. These synthetic milk replacers produced artificial rearing performance similar to that obtained with reconstituted, full-cream cow's milk.

Subsequent studies, both in Europe and North America, have further refined both milk-replacer formulations and management systems for the artificial rearing of lambs. This publication summarizes those findings into practical guidelines for successful artificial-rearing operations.

\section{SELECTING AND PREPARING LAMBS}

\section{MINIMIZING UNNECESSARY ARTIFICIAL REARING}

Do not artificially rear lambs unnecessarily. Artificial rearing of the entire lamb crop is not recommended for commercial operations. It is more economical to let the ewes rear naturally as many lambs as they can raise well and to rear only the surplus artificially. It is also recommended that extra lambs be fostered to other ewes whenever possible. A possible exception to natural rearing occurs when very early rebreeding of the ewes is practiced because lactation may inhibit estrous cycling. In this case the extra lamb production from early rebreeding would have to be sufficient to offset 
the added costs of otherwise unnecessary artificial rearing. Producing three lamb crops in 2 years can be accomplished easily by weaning naturally suckled lambs at 6-8 weeks of age.

An important consideration is to determine which lambs from larger litters should be reared artificially. Previous advice was to pick the larger, more vigorous lambs because it was thought that small, weak lambs had a better chance of survival with the ewe. This recommendation is no longer considered to be valid for two reasons. First, the larger lambs provide the highest return for the ewe's milk because they can take better advantage of her milking ability. Second, extensive research has shown that the smaller lambs can be readily reared artificially, often with greater success than natural rearing. The best compromise is to leave the two (or three if the ewe is an exceptionally good milker and mother) most uniform lambs with the ewe and rear the remainder artificially.

\section{FEEDING COLOSTRUM}

Lambs are born without antibodies in their blood that protect them from common infectious diseases. Antibodies are present in the ewe's first milk (colostrum) and are obtained when the lamb consumes it soon after birth. In addition to supplying essential antibodies, colostrum is rich in nutrients such as vitamins, proteins, and fats to get the newborn lamb off to a good start. It is also a mild laxative, which aids in excretion of the meconium that lines the digestive tract at birth and in starting normal bowel movement.

For about $24 \mathrm{~h}$ after birth, newborn lambs can absorb antibodies intact from their intestine. However, the absorption mechanism begins to shut down soon after the lamb has had its first feed, and soon the antibodies are digested before they can be absorbed. It is important therefore, that the first feed the lamb receives is colostrum, not a milk replacer or sugar solution.

Lambs intended for artificial rearing should be allowed to nurse their mother's colostrum for at least $6 \mathrm{~h}$ before they are removed from her. If for any reason the lambs cannot get colostrum from their mother, excess colostrum can be hand-milked from another ewe and fed either by bottle or by stomach tube. Frozen colostrum, warmed to body temperature and bottle fed, is an adequate alternative. Although frozen ewe's colostrum is preferred, frozen cow's colostrum also provides adequate antibodies for rearing lambs. At least $50 \mathrm{~mL}$ of frozen colostrum per kilogram of body weight is necessary to provide effective resistance to disease. When thawing the colostrum, take care not to overheat it, because heating above body temperature $\left(40^{\circ} \mathrm{C}\right)$ will destroy some of the antibodies.

The concentration of antibodies in colostrum decreases with each milking after birth. Therefore, collect and freeze excess colostrum as soon as possible to ensure a high level of antibodies. 


\section{REMOVAL FROM THE EWE}

Remove lambs to be reared artificially from their mothers as soon as it is certain that they have received adequate colostrum. Nursing the ewe for $6 \mathrm{~h}$ is normally sufficient. However, if the ewe does not have enough milk for all her lambs at this time, feed extra colostrum by a nipple bottle or stomach tube as already noted.

The sooner the lambs are removed from their dams, the easier they will be to train. After $48 \mathrm{~h}$ the bond between mother and offspring becomes so strong that separation is traumatic. By then the nursing reflex is also strongly developed in the lambs making it hard to teach them to drink from an artificial teat. Is is also more difficult to dry off the ewes without causing udder injury.

As soon as the lambs are removed from their mothers, place them in a warm, dry pen, free from drafts and far enough away that they can neither hear nor see the ewes. Provide a minimum pen space per lamb of $0.2 \mathrm{~m}^{2}$. Pens with expanded metal or wire mesh floors are often used, but floor pens that are kept well bedded are satisfactory, provided more space is allowed per lamb $\left(0.5 \mathrm{~m}^{2}\right)$. The temperature of the room should be near $20^{\circ} \mathrm{C}$ for the most efficient utilization of nutrients and rapid weight gains.

Provided the lambs have received colostrum, leave them for several hours without feed before introducing them to the artificial teat. Fasting for about $6 \mathrm{~h}$ is recommended to make training easier. Start the small or weak lambs after $2-4 \mathrm{~h}$ of fasting. When the lambs are hungry the first taste of milk replacer usually starts them sucking.

\section{TEACHING LAMBS TO DRINK MILK REPLACER}

To teach a lamb to drink, place a nipple in its mouth and move its jaws by hand to stimulate sucking (Fig. 1). Many ewes will gently nuzzle their newborn lambs on the rump to guide them to the teat to obtain their first meal. Some shepherds believe that placing a hand on the lamb's rump and gently pushing it to imitate the action of the ewe will stimulate sucking. With most lambs the taste of milk from the artificial teat will start the sucking reflex. Lambs usually need only one or two training sessions, but watch all group-housed lambs carefully during the first few days to ensure that they are all drinking successfully. A light over the feeding area will attract the lambs and help them adapt more quickly to the feeding system.

Either warm or cold milk replacer may be used while training the lambs to nurse from an artificial teat. There is, however, an advantage in starting the lambs on milk replacer of the same temperature that will be used throughout the program. While lambs may suck warm milk replacer more readily during training, there can be problems of rejection and of retraining if they are later switched to cold milk replacer. For similar reasons, the nipples used during the initial training should also be the same as will be used later. 


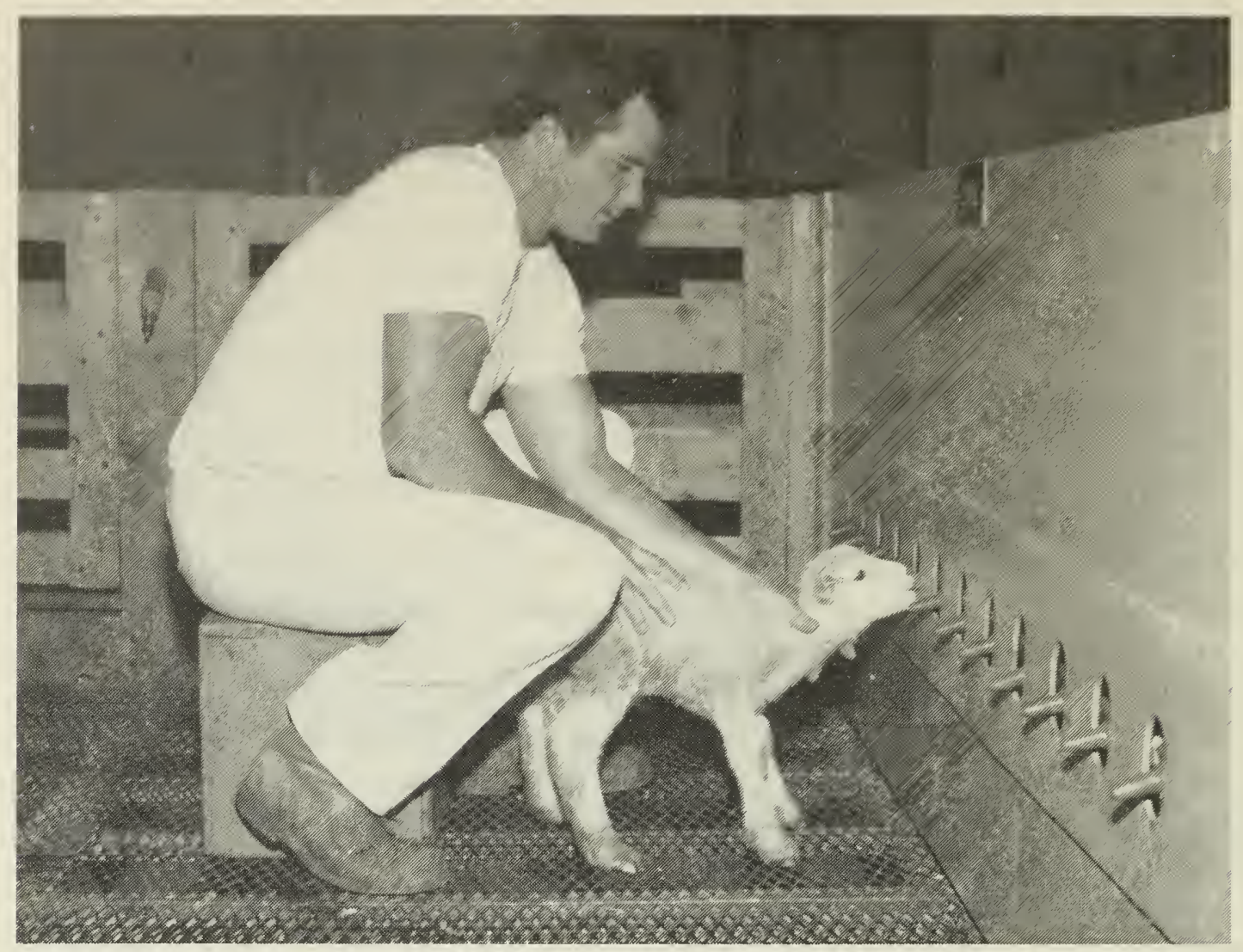

Fig. 1 Training a lamb to suck from a nipple bar (from Ainsworth et al. 1987).

Avoid giving newborn lambs too much attention because a social bond may be established between lambs and their attendant. If this happens, they may drink milk replacer only while the attendant is present or nearby and they show distress when left alone. Although it is important to see that newborn lambs are comfortable and feeding regularly, take care not to make them dependent on the presence of their caretaker. One pet lamb that follows you everywhere may be cute, but what do you do with a whole flock!

The presence of one or two lambs that have already learned to drink milk replacer will help to teach new lambs. However, take care when selecting the trained lambs. If they are much larger than the new lambs, they may be adopted as substitute mothers. The new lambs may then attempt to suck the navel or scrotum of the older lamb. If this practice starts, the lamb that is sucking will usually have to be removed from the group and fed by itself until it learns to nurse the artificial teat.

Lambs that have not adapted to the feeding system within $48 \mathrm{~h}$ probably never will and, unless they are hand-fed, will starve to death.

Experience has shown some differences between breeds in the ease with which lambs learn to nurse the artificial teat. Lambs from the Dorset and Finnish Landrace breeds and their crosses adapt easily, for example. However, lambs from more than 30 breeds and crosses have been raised successfully on milk replacers showing that with proper attention most, if not all, breeds of lambs can be reared artificially. 


\section{GROUPING LAMBS BY SIZE AND AGE}

Better performance can be expected if lambs are fed in groups of 12 or fewer, although larger groups of 25-50 lambs have been reared successfully in many enterprises. The main disadvantage to larger groups is the greater incidence of navel and other nonnutritive suckling. Avoid penning newborn lambs with lambs that are more than 1 week old because a young lamb may adopt an older lamb as its mother and attempt to nurse it rather than the artificial teat.

Group lambs together that are as uniform as possible, both as to size and age. Once a group of lambs has been formed, social bonds will be established among them. If possible, allow lambs to remain together throughout the growing period. They will do better if they are not subjected to the stresses of "pining" for previous friends or partners and reestablishing new ones. After weaning from milk replacer it is usually more efficient to provide solid feed to larger groups. Disruption of social bonds is minimized if two or more groups of lambs are merged intact, rather than mixing a few lambs from each of several small groups into a larger group.

\section{ARTIFICIAL REARING MANAGEMENT}

\section{FEEDING TECHNIQUES}

Bottle-feeding by hand can be used successfully for artificial rearing. If this method is chosen, feed the lambs to appetite every $6 \mathrm{~h}$ for the first 3-4 days. Thereafter, feed them at least twice and preferably three times a day. Bottle-feeding by hand does allow restricted feeding of milk replacer after the lambs are 3-4 days old. This method has the dual advantage of reducing the cost of milk replacer and reducing the growth check at weaning (discussed in the section on "Weaning lambs early"). However, if more than a few lambs are involved, the labor costs rapidly become prohibitive. Then an ad libitum feeding technique, which features a supply of milk replacer available at all times so that the lambs can satisfy their appetite at will by self-feeding, is necessary to reduce labor costs. Therefore, the concepts and guidelines presented in this bulletin apply especially to ad libitum feeding techniques. Most can be adapted to bottle-feeding by hand should that be the technique of choice.

Many systems (see "Feeding systems") ranging from nipple pails to teat bars to sophisticated pipelines, are available for ad libitum feeding. The choice of system depends on the number of lambs to be reared and individual circumstances or preferences. Regardless of the system adopted, each nipple can feed at least four or five lambs (Fig. 2). In experimental work, up to 10 lambs per nipple have successfully been reared artificially. 


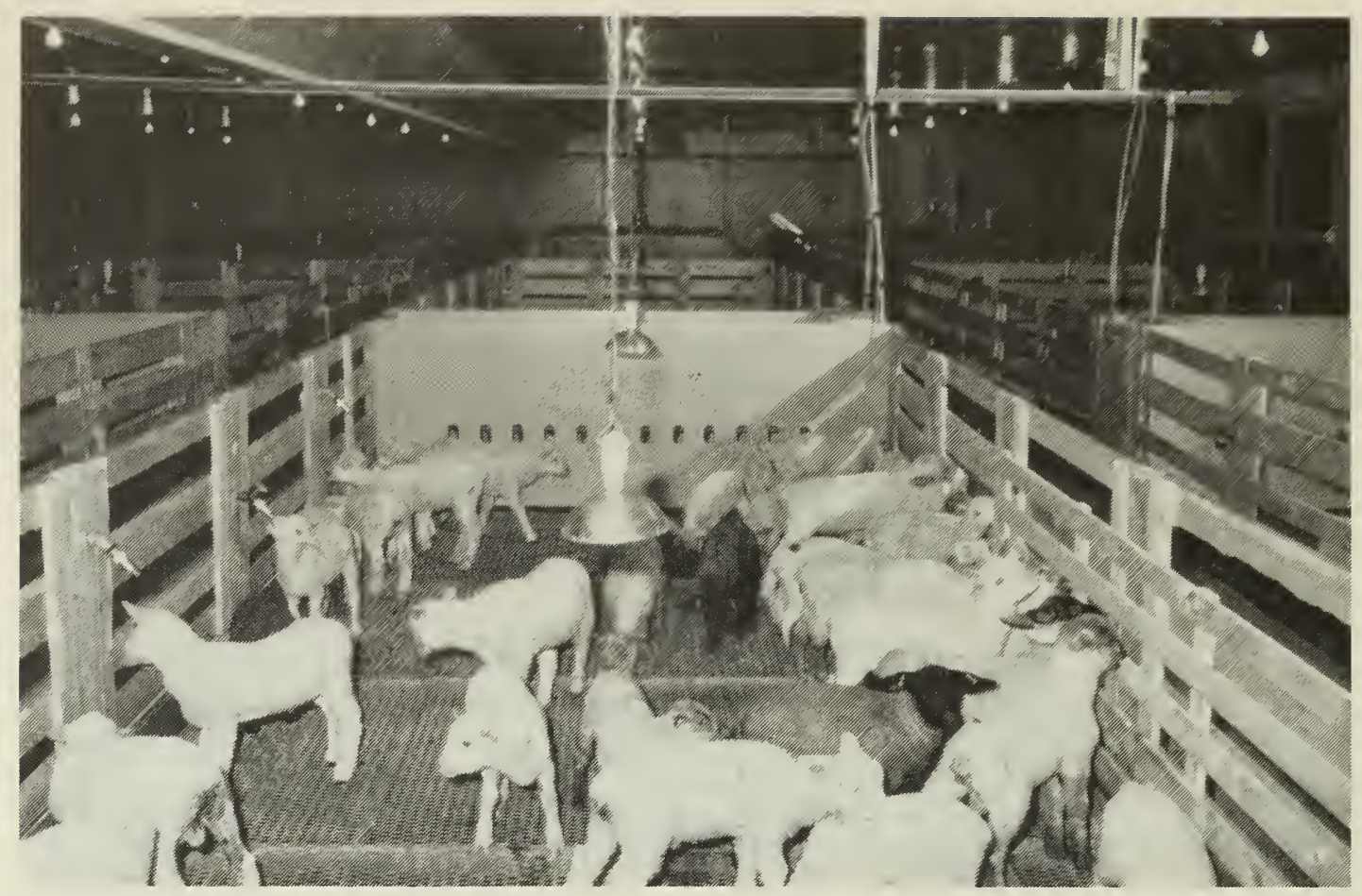

Fig. 2 Pen of lambs fed milk replacer (from Ainsworth et al. 1987).

\section{WATER AND CREEP FEED}

It is very important that the lambs be given both water and a palatable, high-quality creep feed throughout the time that they are on liquid food. Although they will not consume much creep feed, what they do eat will get them used to solid feed and start development of the rumen. Both are essential for a satisfactory transition from liquid to solid food.

The creep-feed concentrate should contain $17-20 \%$ crude protein. It should also be low in crude fiber and high in energy. Glucose or molasses are highly palatable sources of energy. The concentrate may be offered in either a loose mix or pelleted form. Pelleted creep feed prevents the tendency to sort out individual ingredients of the diet. However, it is recommended that pellets be crumbled because very young lambs will sometimes refuse hard pellets. Offer high-quality, fine-stemmed alfalfa hay, as well as the concentrate.

Commercial calf starter-grower, pig starter (providing it contains no added copper), and lamb starter with a high crude-protein content have been used as lamb creep feeds with satisfactory results.

Keep the creep feed fresh and do not allow it to become contaminated with manure or mold. Remove old creep feed and place fresh feed in the feeders daily. Design and locate the creep feeders so that the lambs cannot stand in them. One way is to hang the containers outside the pen and provide an opening for the lamb's head. Make the opening $12-15 \mathrm{~cm}$ from top to bottom and $30-35 \mathrm{~cm}$ above the pen floor. 


\section{TEMPERATURE OF MILK REPLACER}

Feeding warm milk replacer ad libitum often leads to digestive upsets, particularly abomasal bloat, which can cause death, usually of the largest and best-doing lambs, with losses of up to $30 \%$. The condition seems to be associated with excessive distension of the abomasum caused by overeating. Lambs fed warm milk replacer ad libitum usually eat less frequently but overeat when they do nurse.

The need to reduce labor costs by a safe method of ad libitum feeding led to the development of feeding the milk replacer cold. Cold milk replacer fed ad libitum kept longer without souring, eliminated the abomasal bloat associated with warm milk replacer, and provided similar performance by lambs. Lambs fed cold milk replacer drink less at a time but nurse more often so that their total intake over $24 \mathrm{~h}$ is similar to that achieved with warm milk replacer. Thus, the standard recommendation has become that milk replacer should be fed cold, about $4^{\circ} \mathrm{C}$, when given to lambs in an ad libitum system (see "Feeding systems").

The addition of formalin to milk replacer, to retard bacterial growth and delay souring, has also been recommended consistently for commercial artificial rearing of lambs. Studies at the Fredericton Research Station showed that the addition of up to $0.10 \%$ formalin to warm milk replacer also markedly reduced abomasal bloat and had no adverse effect on lamb performance, nutrient usage, or digestive tract mucosa.

Feeding warm milk replacer was subsequently tested at ARC in experiments involving nearly 2000 lambs. Half the lambs were fed cold milk replacer and the other half warm milk replacer. Formalin was added to each mixed milk replacer at the rate of $0.10 \%$. The lambs were healthy and vigorous on both treatments. No cases of abomasal bloat or other digestive disturbances occurred with the two milk replacers, and survival rate was the same. The lambs fed the warm milk replacer consumed $1.2-1.4 \mathrm{~kg}$ more and were slightly heavier at weaning than those fed cold milk replacer. Thus, the reduced labor costs associated with ad libitum feeding can be achieved safely with either cold or warm milk replacer with similar lamb performance.

The choice of feeding method depends on an assessment of the cost advantages or disadvantages and has to be made by individual producers. Feeding warm milk replacer with formalin allows, on the one hand, the use of simpler and less-expensive equipment by eliminating the cost of refrigeration. Thus, reduced labor costs associated with ad libitum feeding can be safely realized. On the other hand, it requires about $1.2-1.4 \mathrm{~kg}$ extra milk-replacer powder per lamb weaned. Extra lamb gains associated with the higher intakes might help defray some of the cost of the extra milk replacer. However, this benefit could not be depended upon because the experimental results indicated that compensatory growth postweaning may wipe out the advantage. If formalin is used, see the section on "Adding formalin" for recommendations. 


\section{WEANING LAMBS EARLY}

Because milk replacer is expensive, keep the duration of feeding liquid as short as possible. Most lambs can be successfully weaned from milk replacer at 3 weeks of age. However, a check in growth occurs during which the lambs lose some weight for about 1 week before resuming normal gains. From then on, rates of gain are nearly identical to those of lambs weaned later.

The growth check is essentially eliminated when weaning is delayed 1 week, which results in about an extra $1.5 \mathrm{~kg}$ of liveweight per lamb at marketing. However, the extra week on liquid feed requires $3.0 \mathrm{~kg}$ more milk replacer powder per lamb. Prices of either milk replacer or lamb are unlikely to change enough in the foreseeable future for the extra lamb weight to recover the cost of the extra milk replacer. Therefore, delaying weaning for 1 week (from 3 to 4 weeks of age) cannot be justified economically.

Possible exceptions are lambs that are still very small at 21 days of age. Experience has shown that lambs that are less than $6 \mathrm{~kg}$ liveweight at 21 days of age (usually less than $4 \%$ of the population, and lambs with very small birth weights) benefit from an extra week or two on milk replacer.

It is particularly important at weaning to be sure that all lambs have found the water. Some lambs that have been doing well on liquid feed may not have started drinking water. If corrective action is not taken, death from dehydration can occur.

Weaned lambs should be fed high-energy diets to maximize daily gains and feed efficiency, to reduce overhead costs, and to shorten the time required to reach market weight. The growing-finishing ration should contain about $17 \%$ crude protein until the lambs are about 100 days of age and $14 \%$ thereafter until they reach desirable market weight and grade.

Keep the creep ration in front of the lambs for the first day postweaning. Then gradually mix increasing proportions of the growing-finishing ration with the creep until a complete changeover is achieved by about 1 week postweaning.

The stress of weaning is reduced if lambs are left in their milkfeeding pens for about 2 weeks after weaning. Afterwards they may be moved into larger pens or feedlot-type facilities.

\section{CHOICE OF MILK REPLACER}

\section{TYPES}

Specialized industrial equipment is required for the satisfactory production of milk replacers. Fortunately, several major feed companies now distribute good-quality milk replacers formulated for lambs, as well as high-quality milk replacers for calves, which can 
also be used successfully for lambs. Producers, therefore, have little reason or economic justification to consider preparing their own milkreplacer powders. Hence, this discussion focuses on the points to be considered when purchasing milk replacer.

The best lamb performance is obtained by feeding milk replacers containing at least $24 \%$ fat and $24 \%$ protein, in which all the protein is provided by spray-dried milk products.

Skim-milk powder is the major source of protein in most commercial milk replacers for lambs. Good-quality, low-heat, spraydried skim milk is essential. High heat treatment of skim milk before or during spray-drying reduces the ability of the milk protein to clot in the lamb's stomach, which has an adverse effect on its feeding value for baby lambs. No evidence has been found to indicate maximum temperatures for safe drying. Therefore, the temperature used for producing human-grade skim-milk powder is recommended.

Buttermilk powder is an excellent alternative to, and is often a cheaper source of milk nutrients than, skim-milk powder. Many companies replace varying proportions of skim-milk powder with buttermilk powder in their formulations as the relative prices of the two ingredients change. Within reasonable limits, skim-milk and buttermilk powders appear interchangeable and data indicate no adverse effect on lamb performance from altering their proportions in milk-replacer formulations.

Fat levels of $30 \%$ in the dry powder were once recommended and had become normal in North America. However, research has shown clearly that lambs fed milk replacer containing $24 \%$ fat perform as well as, if not better than, those fed $30 \%$ fat. This decrease in fat content reduces the price of milk replacer by about $10 \%$ because manufacturing costs are lower as less fat is easier to homogenize. Therefore, producers should not hesitate to use the lower fat level wherever such milk replacers are available. The fat can be provided by combinations of high-quality tallow, lard, butterfat, or coconut oil. Other vegetable oils are not recommended.

Milk replacers in which part of the skim-milk powder is substituted by casein and whey or cerelose are also being used successfully. With this type of milk replacer it is recommended that lactose (or total sugar) content be limited to $30-35 \%$ because higher sugar contents have been reported to cause diarrhea. However, when spray-dried skim or buttermilk are used to provide the protein, lactose (or total sugar) content will normally be $40-45 \%$. With such formulations there have been no reports of diarrhea caused by excessive sugar.

Lambs can also be reared successfully either on whole cow's milk, if a cheap source is available, or on high-quality milk replacer for calves. Only high-quality milk replacers for calves, defined as those with at least $20 \%$ fat and $20 \%$ protein with the protein provided entirely by spray-dried milk products, should be considered. Lowerquality and, hence, less-expensive milk replacers for calves commonly contain less protein or fat, or both, or part of the protein may be 
provided by plant products. Avoid such lower-quality products because they are unsatisfactory for lambs. Weight gains on whole cow's milk or milk replacers for calves are about $90 \%$ of those achieved with specially formulated milk replacers for lambs. Nevertheless, their use can be economical because the lower cost of the feed more than offsets the marginal reduction in lamb performance.

Another possibility is a half-and-half mixture of cow's milk and reconstituted milk replacer for lambs. The performance of lambs fed this mixture is identical to that achieved when only milk replacer for lambs is fed.

In the United States, relatively high levels of antibiotics (for example, neomycin at $275 \mathrm{mg} / \mathrm{kg}$ ) have been recommended to avoid diarrhea and other digestive disorders. Lower levels (chlortetracycline at $55 \mathrm{mg} / \mathrm{kg}$ ) have also been routinely used in experimental formulas. However, antibiotics have never been used in the artificial rearing operations at $A R C$. Nontherapeutic levels of antibiotics are not needed in milk replacers for lambs and, hence, are not recommended provided that good sanitation and management practices are followed.

\section{PREPARATION}

Reconstitute commercial milk replacers according to the manufacturer's instructions. One part by weight of milk-replacer powder mixed with four or five parts by weight of water gives the 16-20\% solids usually recommended. When mixing milk replacer, first add about half the required water hot, at about $50-55^{\circ} \mathrm{C}$, to ensure that the powder dissolves completely and that the fat globules remain homogenized. Do not use water hotter than $55^{\circ} \mathrm{C}$ or the protein will be damaged. After thorough mixing with hot water, add the remaining water cold and mix thoroughly. Refrigerate the mixture before feeding it to lambs if the milk replacer is to be fed cold, or cool it to body temperature if it is to be fed warm.

\section{ADDING FORMALIN}

There are several advantages to adding low levels of formalin to milk replacer. Formalin retards bacterial growth and delays souring of reconstituted milk replacer. It also prevents, or greatly reduces, abomasal bloating in lambs that are fed warm milk replacer. For lambs it is recommended that $0.05-0.10 \%$ of formalin be added to the reconstituted milk replacer. At these low levels formalin does not produce any adverse effects.

If formalin is added, first mix the milk replacer powder with warm water in the usual manner. Then add the formalin and mix thoroughly. To obtain a level of $0.10 \%$, add formalin at $1 \mathrm{~mL} / \mathrm{kg}$ (or $1 \mathrm{~mL} / \mathrm{L}$ ) of liquid milk replacer. Half this amount of formalin will provide a concentration of $0.05 \%$ in the milk replacer. Use a syringe to 
measure the correct amount of formalin. Do not add more than $0.10 \%$ formalin because higher concentrations are unpalatable to lambs and will result in reduced intake and poor performance.

Formalin is a solution containing formaldehyde at $35 \%$ by weight. Because it is a noxious chemical, handle it carefully to prevent injury. Fumes from formalin are irritating to the eyes and nose. If it comes in contact with your skin, wash thoroughly; if it gets into your eyes, wash them with running water for $15 \mathrm{~min}$ and call a doctor. By taking reasonable precautions, formalin is no more hazardous than other chemicals commonly used on the farm.

\section{FEEDING SYSTEMS}

\section{PROTECTING THE NIPPLES}

Damage to nipples from lambs chewing them can be extensive, especially as the lambs get older. Chewing damage almost invariably results from lambs being able to grasp the nipples from the side with their back teeth (molars). Substantial milk loss can occur unless such chewing is prevented. When using an ad libitum feeding system, protect the nipples with metal or plastic shields to prevent lambs from chewing holes in the nipples from the side (see Figs. 5-8). Plastic shields made from empty, and carefully cleaned, plastic bottles are effective in protecting the nipples. The shields may also help guide the lambs to the nipples as they learn to nurse. Recessing the nipples behind holes that are $8-10 \mathrm{~cm}$ in diameter (or better yet, $6 \mathrm{~cm}$ wide by $10 \mathrm{~cm}$ high), cut out of plywood so the la mb can only reach the nipple by putting its nose into the hole, also protects the nipples (Fig. 1). Mounting the nipples through a metal or wooden plate that has baffles on each side of the nipples, about $8-10 \mathrm{~cm}$ apart, has also been reported to prevent chewing.

\section{FEEDING FROM A NIPPLE PAIL}

A nipple or nipples can be fitted easily on a bucket or other plastic container by cutting a hole, or holes, in the side near the bottom of the container (Fig. 3). Hang the bucket on the pen partition so the lambs can help themselves. The advantages of this simple system are low cost and ease of cleaning. The contents can be kept cold by floating a plastic bottle full of frozen water or a commercial cold bag in the milk replacer. The chief disadvantage is that it is difficult to protect the nipple (or nipples) from being chewed by the lambs, and damage to a nipple can result in leaking and the loss of all the milk replacer in the container. 


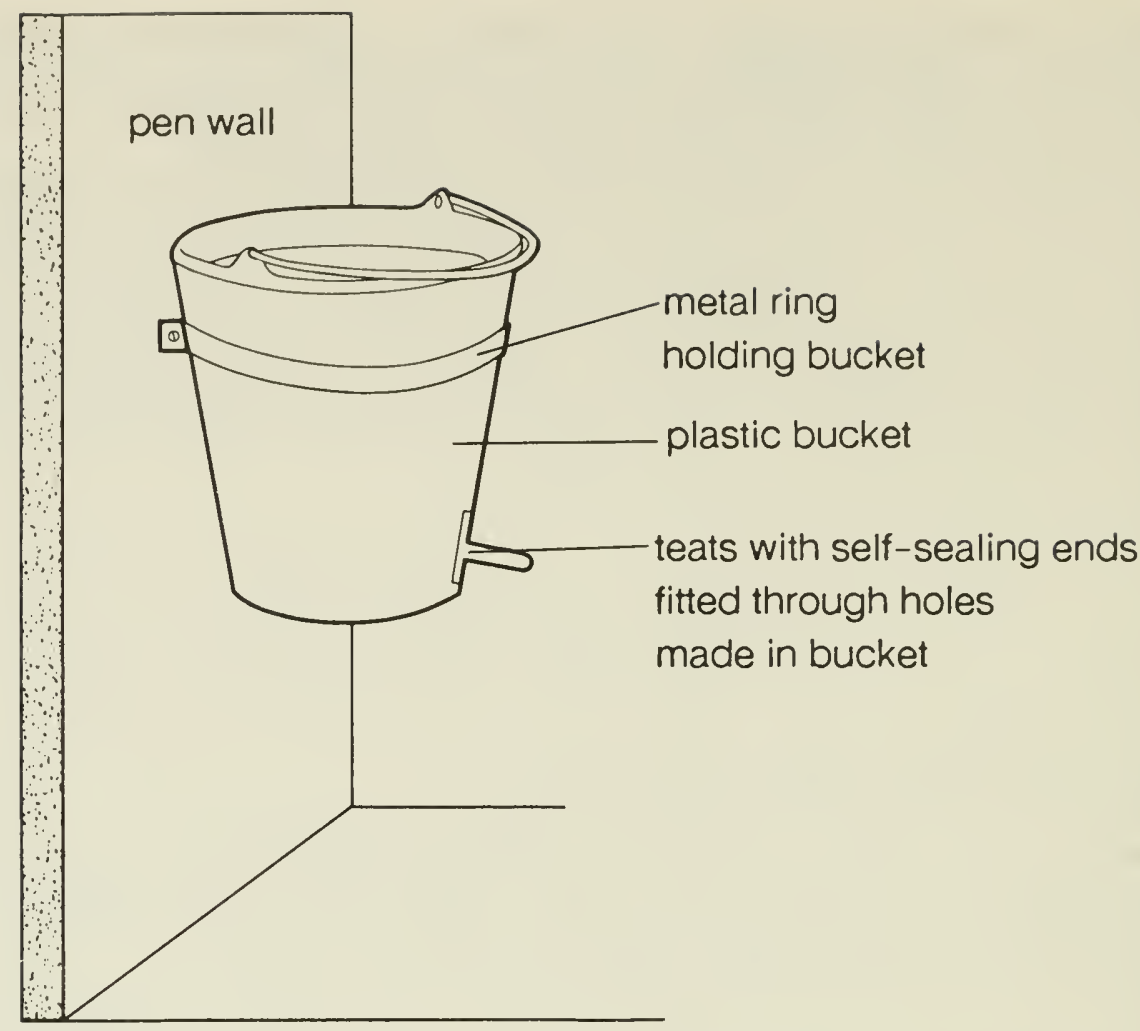

Fig. 3 Inexpensive bucket feeder for small groups of lambs (from Spedding et al. 1976).

\section{MULTIPLE-NIPPLE CONTAINERS}

The nipples can be attached to a metal or plastic connector fastened to a hole in the pen partition and connected by a plastic tube to the milk supply in a bucket or other container (Fig. 4). Several nipples can be supplied from one container. If the container is kept below the level of the nipple, no milk is lost if the nipple is damaged. The chief disadvantage is that teaching lambs to drink from this system is more difficult because they must suck long and hard enough to draw the milk replacer up the supply line to the nipple. Many small weak lambs will not do this. Installing a simple foot valve to prevent milk replacer from draining back down the tube helps, but keeping the valve working efficiently may be difficult. The valve can be made by putting a ball bearing on top of the barrel of a ballpoint pen inserted into the bottom of the supply tube. Commercial valve units are also available from automobile supply stores (for windshield washers) and from hardware or appliance stores.

A commercial unit is also available with nipples fitted to the bottom of the container so that the milk replacer flows by gravity and several lambs can feed at once. The milk can be kept cold by plastic ice bags or bottles. 


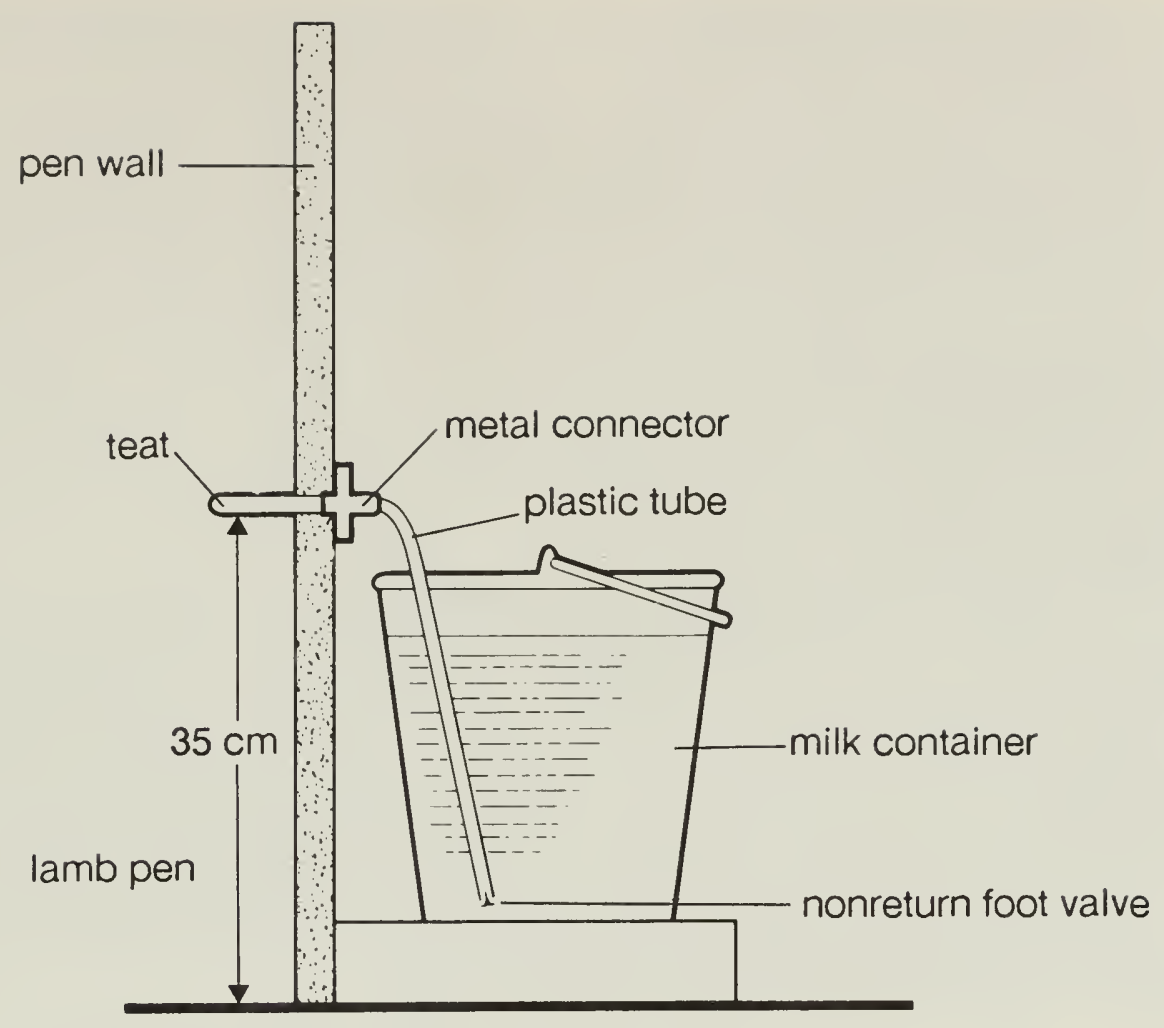

Fig. 4 Simple equipment for feeding groups of lambs; if teat is damaged, milk replacer will not be spilled, as it would with the system shown in Fig. 3 (from Spedding et al. 1976).

\section{TEAT BARS}

Teat bars such as those shown in Figs. 5-8 are relatively easy and inexpensive to build. They can be assembled from readily available plastic plumbing supplies. A teat bar consists of nipples attached to pipes or tubing through which milk replacer flows by gravity or is circulated by pump from a bulk supply. The milk replacer can be refrigerated, heated, or left at room temperature.

Nipples used on a teat bar must be designed or modified so that they do not leak when filled with liquid milk replacer. Lamblux ${ }^{\circledR}$ nipples (Fig. 5) and baby soother nipples (Fig. 7) with a small vertical slit cut by a sharp blade have been used successfully on teat bars.

An inexpensive teat bar used at the Fredericton Research Station (Figs. 5 and 6), was made from 1.25-cm flexible plastic tubing. Standard $1.25-\mathrm{cm}$ hard plastic Ts were inserted at $20-\mathrm{cm}$ intervals. The part of the $\mathrm{T}$ to which the nipple is attached was shortened to only one or two ridges so that the hard plastic did not slide too far into the nipple. The far end of the tubing was left open, as can be seen in Fig. $5 a$, so that pressure did not build up in the system and cause leaking at the unused nipples when a lamb sucked on another nipple. A minimum of six nipples per teat bar was found to be necessary to 


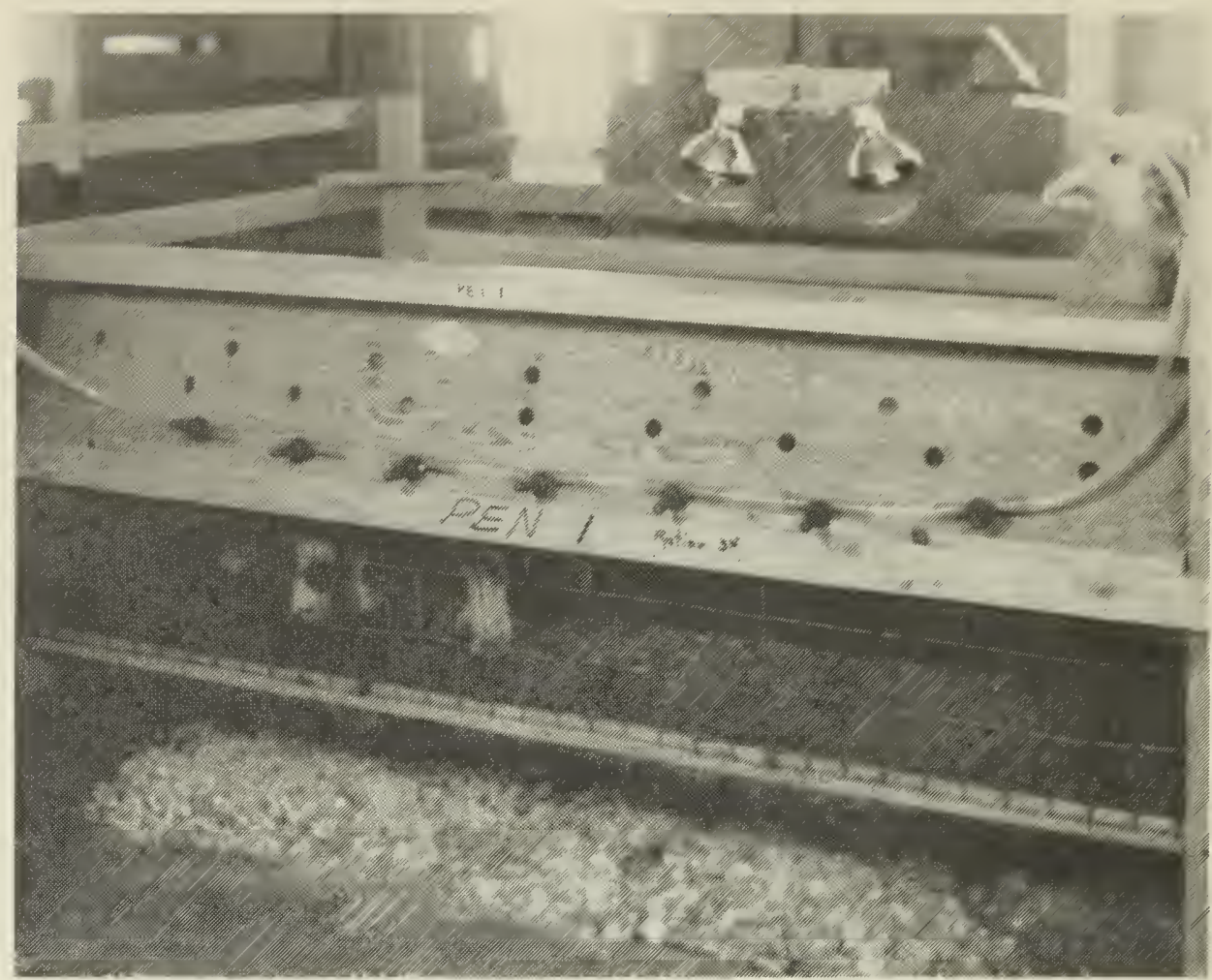

b

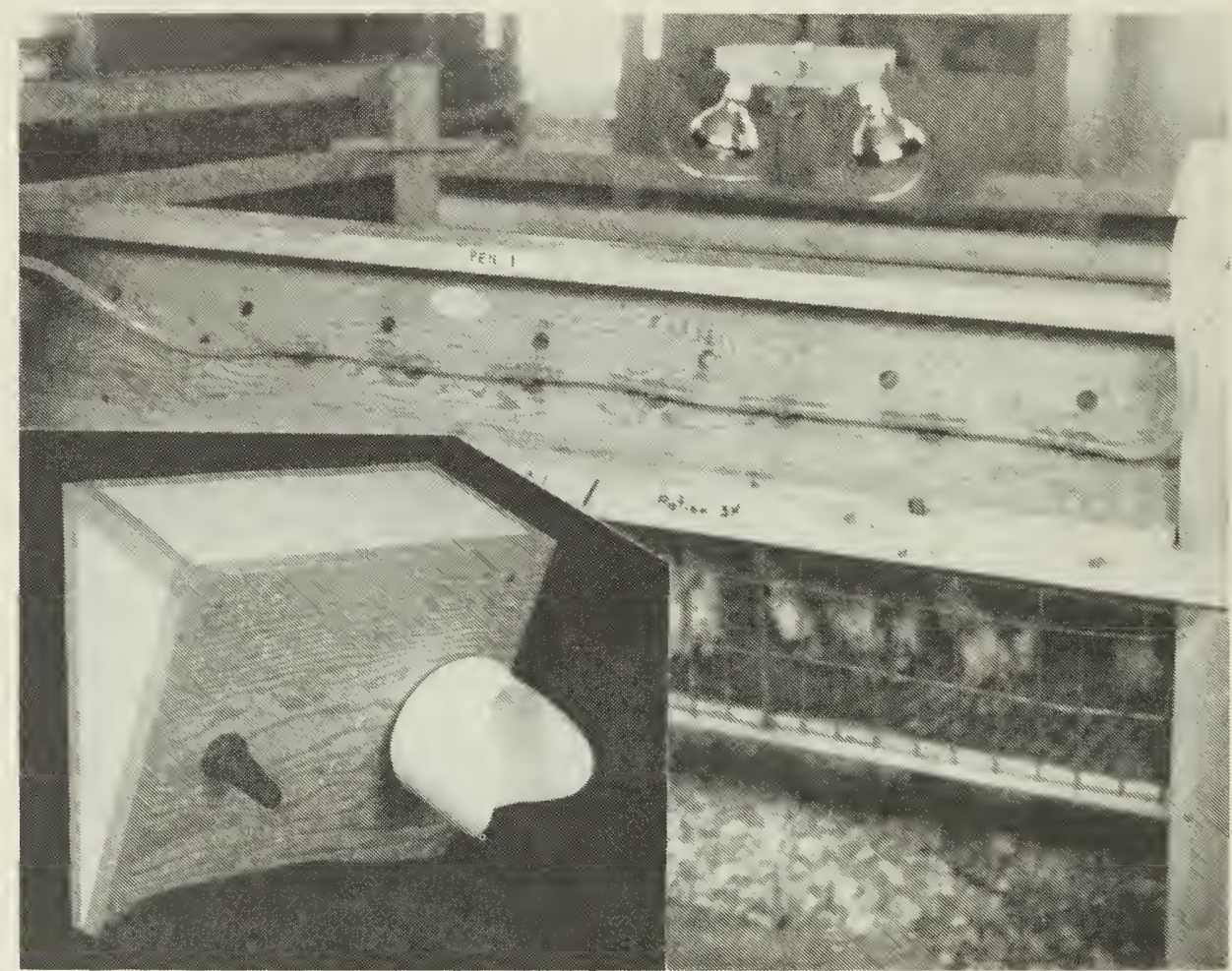

Fig. 5 (a) Teat bar for a small group of lambs showing Lamblux ${ }^{\circledR}$ nipples, not yet inserted into holes for feeding; the plastic tubing is $1.25 \mathrm{~cm}$ in diameter; the right end (arrow) has been left open to prevent pressure buildup in the system. (b) Teat bar showing nipples inserted into $2.5-\mathrm{cm}$ diameter holes in a plywood board. Nipples (inset) protrude through the downward-tilted board, with and without a plastic shield; the shield was cut from the bottom of a 1-L detergent bottle. 


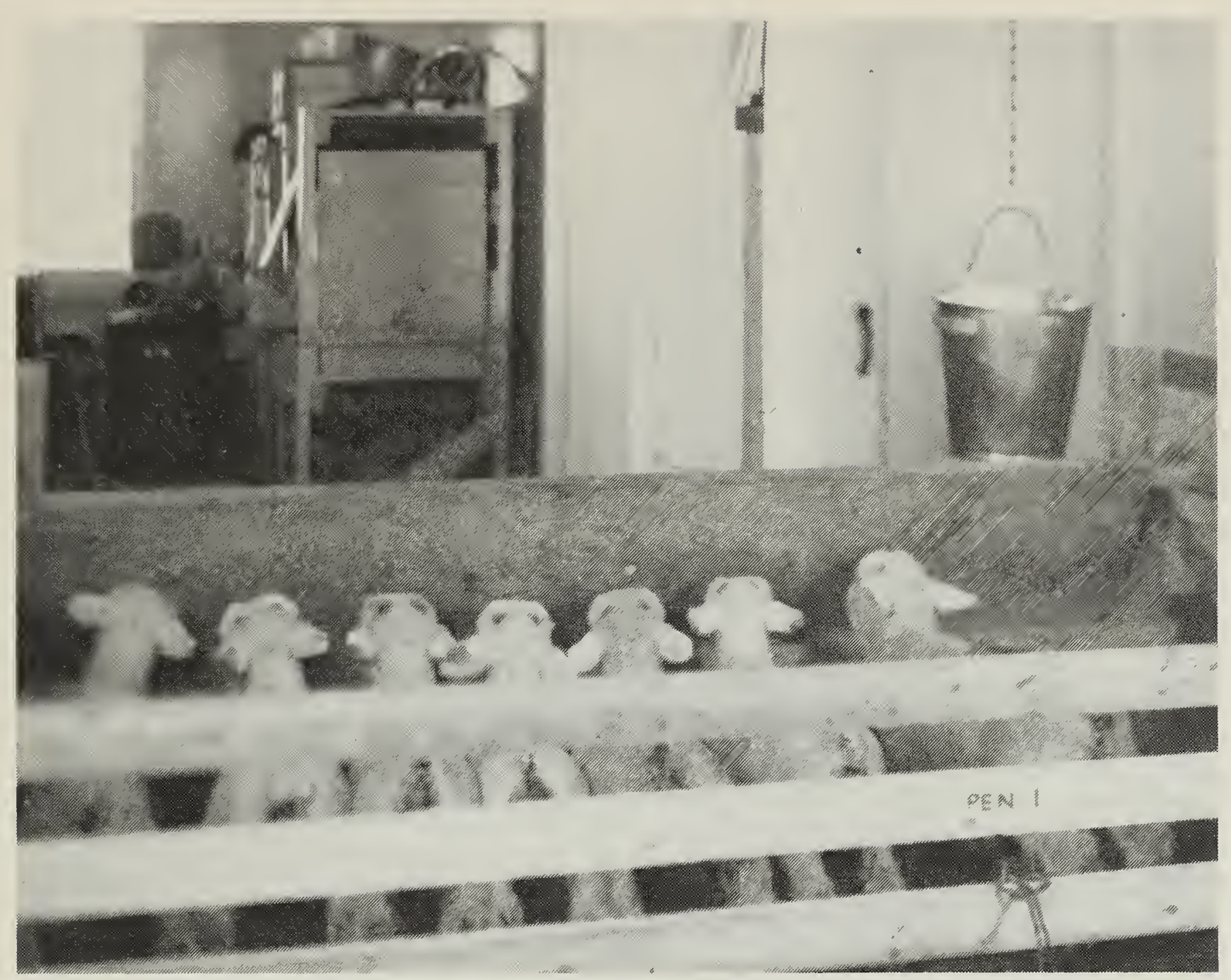

Fig. 6 Lambs sucking warm milk replacer through nipples on the teat bar shown in Figs. $5 a$ and $b$.

prevent leakage from unused nipples when lambs sucked. The board into which the nipples were fitted for feeding (Fig. $5 b$ ) was placed at an angle of about $65^{\circ}$ to approximate the shape of the ewe's udder and teats. The nipples may be farther apart than $20 \mathrm{~cm}$, depending on pen design and number of lambs to be fed, but less than $20 \mathrm{~cm}$ causes crowding.

Rigid pipe has also been used successfully but may be more difficult to clean than the flexible tubing. Teat bars made from rigid tubing are shown in Figs. 7 and 8. The milk supply can be kept in an open bucket at room temperature or it can be refrigerated (Fig. 9). A secondhand refrigerator or small, restaurant-type milk cooler is adequate for holding containers of milk replacer for groups of up to 50 lambs. A hole can be cut in the side of the cooler for the tubing that connects the teat bar with the supply of milk replacer, as shown in Fig. 9.

Continuous circulation of the milk replacer through the teat bar and back to the refrigerated storage keeps the milk supply at a constant cold temperature. A small, inexpensive, plastic, positive-pressure pump (Fig. 9), operated by a variable-speed motor at about $100 \mathrm{rpm}$, was used successfully at the Fredericton Research Station. Small-scale gear pumps operated at low speeds have also been used without problems. A small, centrifugal pump was 
unsatisfactory because it caused excessive foaming and fat separation in the milk replacer.

It is advisable to have some method of shutting off the pump automatically if the supply of milk replacer runs out. The system used to circulate the milk replacer must be designed to exert very little pressure on the nipples, otherwise milk replacer will squirt out of them. In the system shown in Fig. 9, the milk replacer flows by gravity from the refrigerated supply to the teat bar and is pumped back into the container.

a

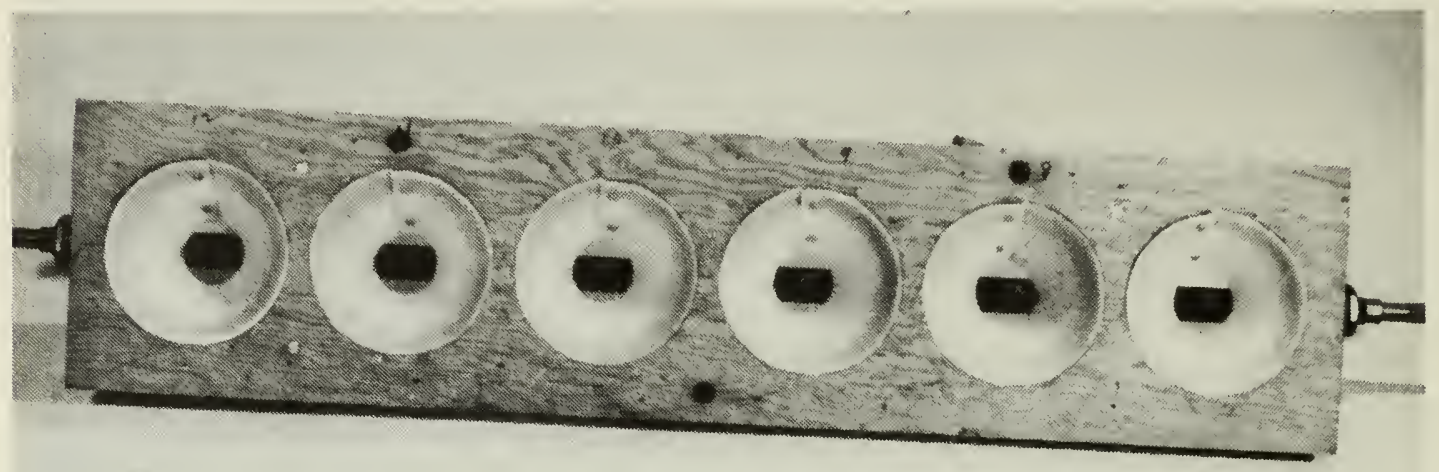

$\mathrm{b}$

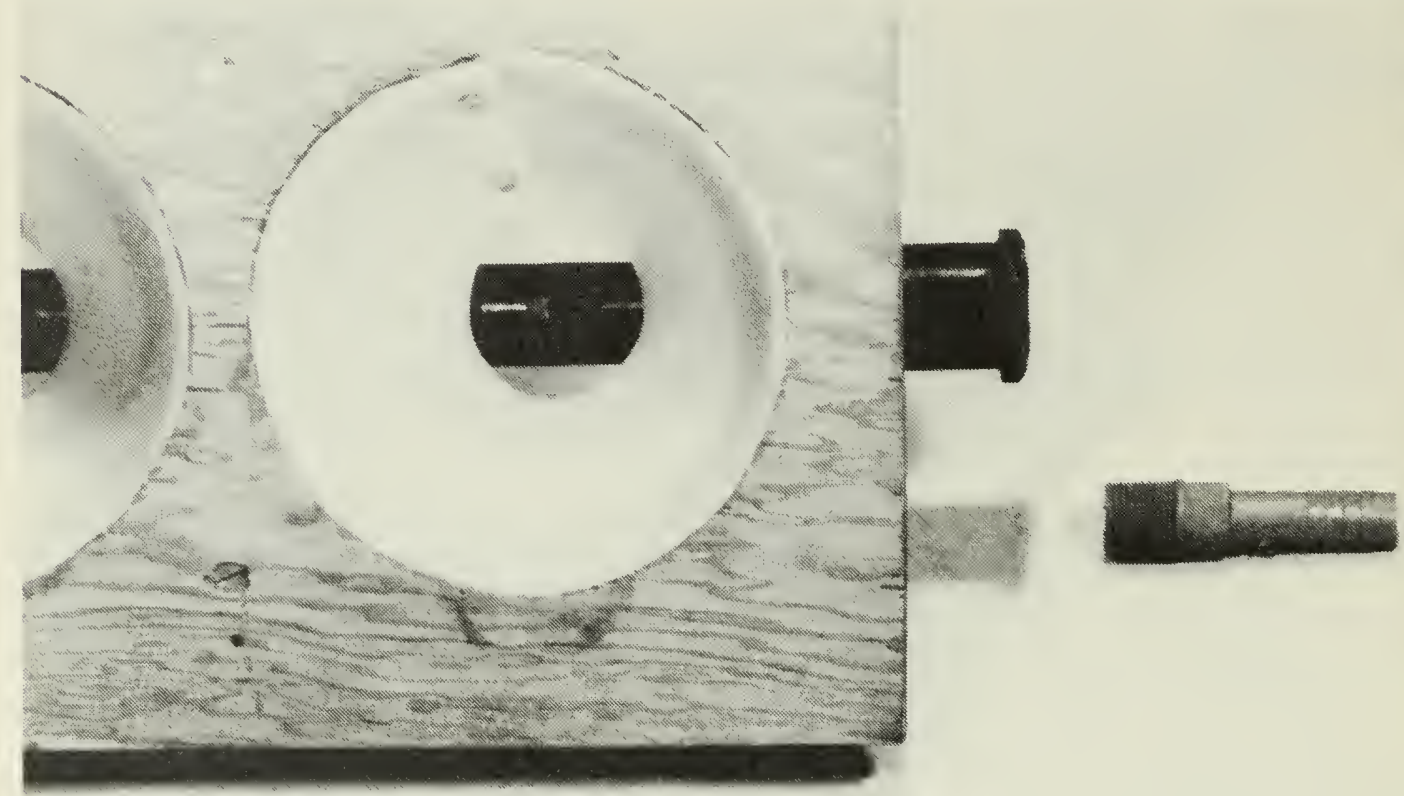

Fig. 7 (a) An alternate type of teat bar; the nipples should be $20 \mathrm{~cm}$ or more apart. (b) Parts of one feeding unit on a teat bar: plastic shield, perforated plastic tube and reducer, plastic bung, and baby soother nipple. 


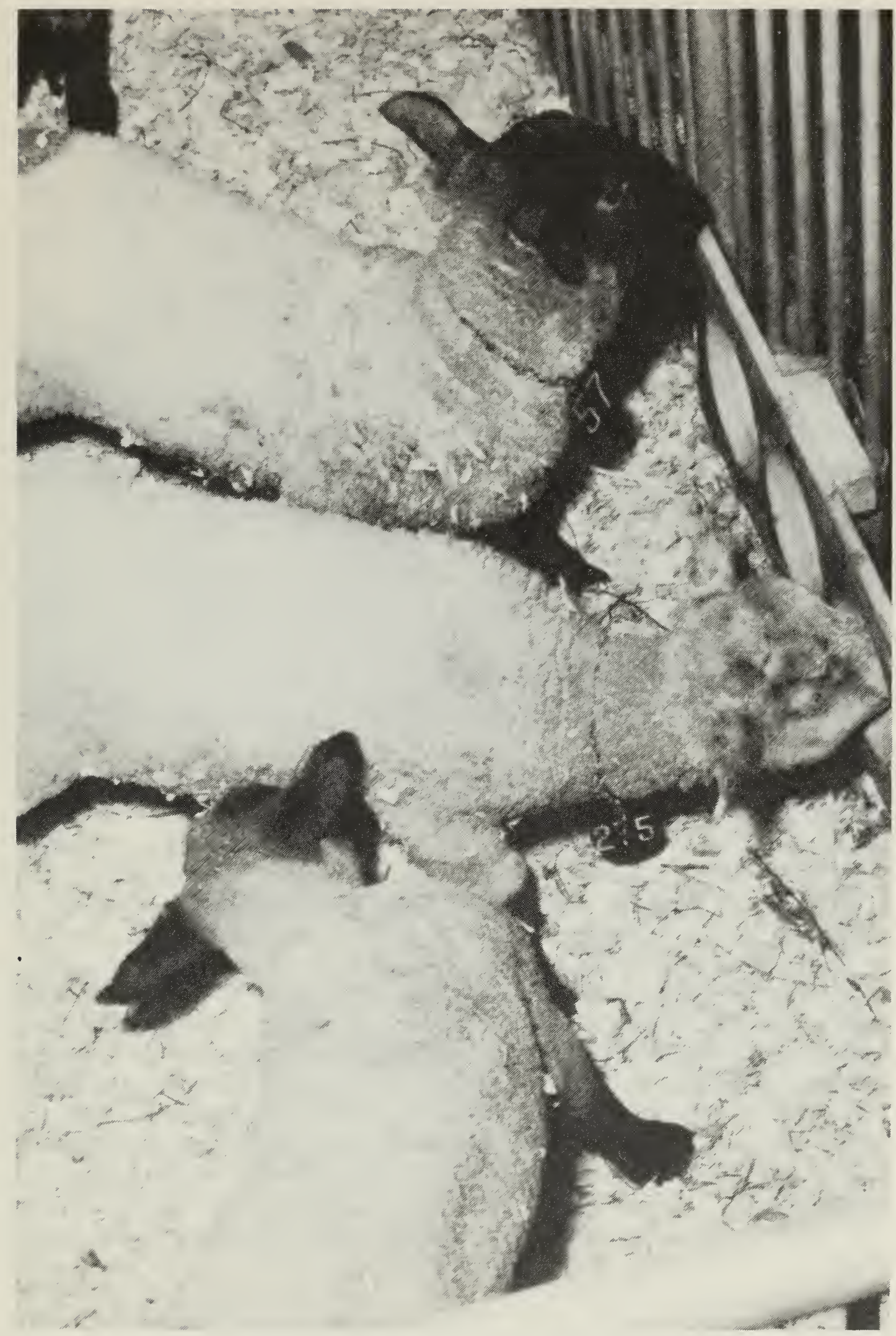

Fig. 8 Lambs sucking cold milk replacer circulating in a teat bar similar to the one shown in Figs. $7 a$ and $b$. 


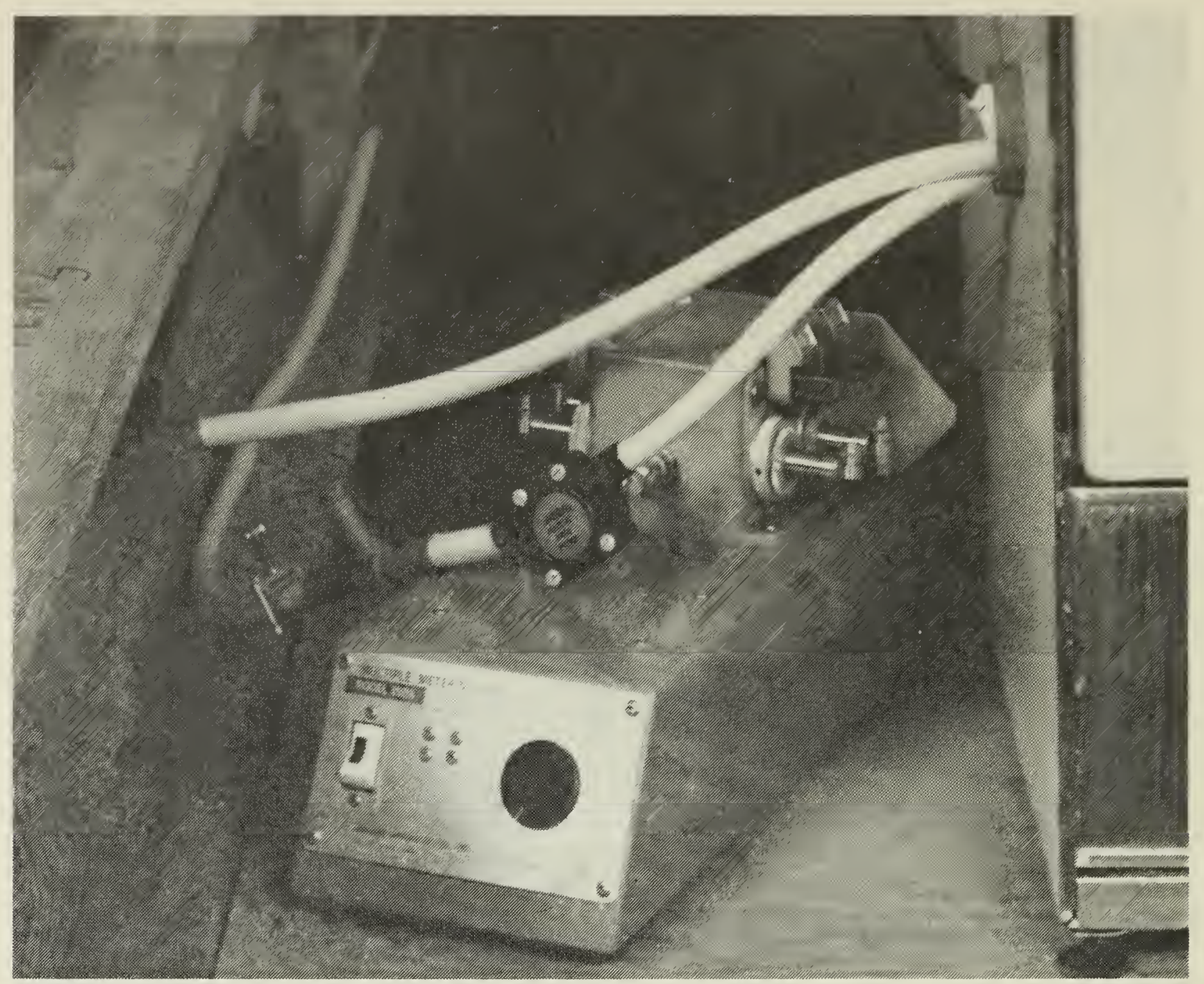

Fig. 9 Plastic pump attached to variable-speed motor; the milk replacer flows by gravity from the container inside the refrigerator to the nipples and is pumped back into the container.

\section{SANITATION AND CLEANING}

For maximum lamb performance, clean all milk-replacer feeding equipment regularly and practice good sanitation. Liquid milk replacer is very susceptible to bacterial growth and will sour quickly at room temperature. It is desirable to clean the nipples and tubing, or lines when they are present, every day. To clean and disinfect any milk replacer utensils, nipples, or other equipment, rinse in turn with cold water, hot water and detergent, hypochlorite solution, or other disinfectant. You may need to use a brush to remove fat during the hot-water wash. Finish with a thorough, cold-water rinse. Be sure to remove completely all traces of the disinfectant. Clean bulk containers two or three times a week, or more often if the milk replacer starts to sour sooner. The actual interval will depend on the type of container, temperature of the milk, and whether or not formalin is used to slow the rate of souring. Elaborate pipeline systems can be cleaned in place at predetermined intervals.

When milk replacer is fed ad libitum, make it available to the lambs at all times, and keep the time required for cleaning and 
sanitizing the feeding system short. For this reason, it is helpful to have a duplicate set of teat bars and nipples, or whatever system is in use. The clean set can be in place while the other one is being washed, and in this way, the lambs are not deprived of milk replacer during washing, which can be done when time permits.

\section{LAMB DISEASES AND DIGESTIVE UPSETS}

An injection of vitamins $\mathrm{A}, \mathrm{D}$, and $\mathrm{E}$ at birth helps to prevent disease and infection. If white muscle or stiff-lamb disease is a problem in your locality, the lambs may be injected with a preparation of vitamin $\mathrm{E}$ and selenium at birth, with a second injection given when the lambs are weaned from milk replacer. Selenium may also be added to the milk replacer powder by the manufacturer. Do not administer supplementary selenium in more than one way; that is, if the milk replacer contains supplemental selenium do not inject the lambs with selenium. Selenium should also be fed to the ewes in their grain ration or in a free-choice mineral mix.

Lambs reared on milk replacer fed ad libitum followed by highenergy solid diets after weaning are subject to overeating disease (pulpy kidney, or enterotoxemia) at 3-4 weeks old. The lambs should be vaccinated with a multiple clostridia or type $\mathrm{D}$ preparation (use one-half the dose recommended for feeder lambs) when they are 7-10 days old. They should be given a booster injection 2 weeks later. Alternatively, the ewe can be vaccinated about 2-4 weeks before lambing. The antibodies produced by the ewe will then be transferred to the lamb through the colostrum. In this case the lambs should be given booster vaccinations at 49-56 days of age.

Abomasal bloat can be a problem with lambs raised on milk replacers. The gas that causes abomasal bloat is produced by a microorganism, Lactobacillus fermentum. The low levels of antibiotics sometimes used in milk replacers for lambs do not control this organism, but it is greatly inhibited by the small amount of formaldehyde $(0.05-0.10 \%$ formalin) recommended for retarding souring (see "Adding formalin").

Diarrhea is not usually a problem when lambs are fed good-quality milk replacers. However, a milk replacer that has both a low-fat and a high-lactose content, or a high content of starch or polyunsaturated fat can cause diarrhea.

\section{PERFORMANCE OF LAMBS RAISED ON MILK REPLACER}

Under good management and feeding conditions, lamb performance on milk replacer has been equal to, or better than, that of 
similar lambs left with the ewe. The growth of lambs fed milk replacer to weaning at 3-4 weeks old is about equal to similar single lambs sucking the ewe and is usually better than for twin lambs sucking the ewe. Daily weight gains should be $0.25-0.30 \mathrm{~kg}$ per lamb during the milk-replacer feeding period. Because competition for milk supply is eliminated with artificial rearing, lambs born in different sized litters (i.e., singles, twins, triplets, and so on) will grow at about the same rate. When weaned lambs are fed high-energy (high-concentrate) diets, gains should remain about the same to at least 100 days of age.

Fast-growing lambs consume up to $0.5 \mathrm{~kg}$ of good-quality milk-replacer powder a day. They are very efficient in converting the milk replacer to body growth and require only about $1.0 \mathrm{~kg}$ of dry milk-replacer powder for each kilogram of body weight gain.

The total amount of milk replacer required to raise a lamb varies with the feeding system, milk-replacer formula, age at weaning from milk replacer, and birthweight. However, lambs fed milk replacer ad libitum to 3 or 4 weeks will generally consume $7-9 \mathrm{~kg}$ of milk-replacer powder per lamb weaned.

The mortality of lambs fed cold milk replacer is generally less than 5\%. There are usually fewer deaths among lambs reared artificially than among those raised with their dams because there is less chance of accidents or inadequate food supply.

\section{ADDITIONAL READING}

Ainsworth, L.; Heaney, D.P.; Fiser, P.S.; Langford, G.A.; Shrestha, J.N.B.; Leger, D.A. 1987. Research and technology for increasing the efficiency and output of lamb production systems. Agric. Can. Tech. Bull. 1987-11E. 85 p. (Available free of charge from Director, Animal Research Centre, Research Branch, Agriculture Canada, Ottawa, Ont. K1A 0C6.)

Frederickson, K.R.; Jordan, R.M.; Terrill, C.E. 1980. Rearing lambs on milk-replacer diets. U.S. Dept. Agric. Farmers' Bull. No. 2270.

Heaney, D.P.; Shrestha, J.N.B.; Peters, H.F. 1983-1984. Reducing the cost of milk replacer for the artificial rearing of lambs. Sheep Canada 8(4):7.

Heaney, D.P.; Shrestha, J.N.B. 1984. Management tips for reducing artificial rearing costs for lambs. Sheep Canada 9(4):3-4.

Hess, E.W. 1971. The milk-bar "foot-valve." The Shepherd 16(3):10.

Sheep Industry Development Program, Inc. 1975. The Sheepman's Production Handbook, 2nd ed. Abegg Printing, Denver, Colo.

Spedding, C.R.W., et al. 1976. Artificial rearing of lambs. Technical Report, Sheep Improvement Service, Meat and Livestock Commission, U.K. 35 p. 
